\title{
A Case Study on Psychological and Physical Stress Undergone By Married Working Women
}

\author{
Bhuvaneshwari M \\ (Department of Civil Engineering, Agni College of Technology, Anna University, India)
}

\begin{abstract}
Women in India have come a long way after independence from just a skilled homemaker to acquired skills and capabilities at par with their male counterparts. But still more conflict arises with the working mother who has to fulfill the demand at work followed by various demands at home. This can leave a working woman anxious and stressed. The past research on the study of stress in working women was dealing with the surveying of working women carried out in various institutions like hospitals, BPO's.,etc. The current study deals with the study of working women at Agni College of Technology (Educational institution). The present study is based on primary data through pilot study. Questionnaire was the main tool for collecting the primary data. The research analysis was carried out by percentage evaluation method. This study revealed that stress in married working women is caused due to long working hours, various family and official commitments, harassments and improper work life balance. Such type of stress leads to various problems such as prolonged headaches, hypertension and obesity. Stress can be relieved from institutional support, balancing work and life by spending time with family, entertainments, yoga and rest.
\end{abstract}

Keywords: physical problems in married women, psychological stress in women, stress causes, stress reduction, working mothers

\section{INTRODUCTION}

Women in India have come a long way after independence. From just a skilled homemaker, women today have acquired skills and capabilities of not just being a homemaker but being at par with their male counterparts. This is the new generation of women, who wants to pursue their dream career. But this life is not a bed of roses for all. [1]. More problems arise with the working mother as she has to fulfill the duties at work as well as home. In today's scenario, it is required for the husband and wife both to work towards fulfilling the financial needs of the family. Hence a common conflict among married working women is that though they work for balancing the family financially, unlike their counterparts they have to play the role of a homemaker also. As societies become more advanced technologically, women depend increasingly on their individual talent and inventiveness for their progress and development. The dual roles of the working women can lead to additional stress in their lives [2] Stress is the psychological and physiological reaction that takes place when one perceives an imbalance in the level of demand placed on the capacity to meet that demand on individuals[3].

IffatHussain[4] assessed the major problems faced by working women as through a series of interviews based on salary levels. Ungsinan Intarakamhang[5]summarized the progress and development of research studies concerning stress and coping of Thai people, and gave the factors affecting stress and coping by synthesizing from research, dissertation, and minor thesis. Qualitative data was synthesized by content analysis presented in percentages. Quantitative data was synthesized by estimating effect sizes through Meta analysis techniques. Vatiswa Veronica Makie [6] has identified the possible causes and frequency of stress experienced by registered nurses working in a Groote Schuur Hospital, South Africa. A descriptive correlational study was used to identify sources of stress experienced by registered nurses, describing the relationship between stress and coping through questionnaires.

The past research on the study of stress in working women was dealing with the surveying of working women carried out in various institutions like hospitals, BPO's.,etc. The current study deals with the study of married working women at Agni College of Technology, an Educational institution. Questionnaire was the main tool for collecting the primary data. The questionnaire was designed in a systematic way for covering adequate and almost all relevant aspects of the study. A sample survey was carried out with a population of 30 married women of age twenty to fifty years, working at Agni College of Technology, OMR, Chennai. The data collected from the primary sources were arranged sequentially and tabulated in a systematic manner. Secondary data required for the study was collected from books, magazines, journals, newspapers, past research, reports and various websites.

\section{Stress Level Based On Age Limit}

The stress level in any individual is greatly influenced by their age. It is found form Table 1 and Fig 1 that the women in the age limit $20-30$ years are stressed to $75 \%$ and the women in the age of $30-50$ years undergo 
$75 \%-100 \%$ stress. This shows that the stress in women increase in direct proportionality to their age, i.e., the increase in age of women also increases their stress. This may be because of the additional responsibilities imposed on the elder women both in the family as well as workplace.

Table 1 Stress Level Vs Age Limit

\begin{tabular}{|c|c|c|c|}
\hline \multirow{2}{*}{ Age Limit } & \multicolumn{3}{|c|}{ Stress Level } \\
\cline { 2 - 4 } & $\mathbf{5 0 \%}$ & $\mathbf{7 5 \%}$ & $\mathbf{1 0 0 \%}$ \\
\hline $20-30$ yrs & 14 & 25 & 11 \\
\hline $31-40$ yrs & 30 & 60 & 50 \\
\hline $41-50$ yrs & 0 & 50 & 50 \\
\hline
\end{tabular}

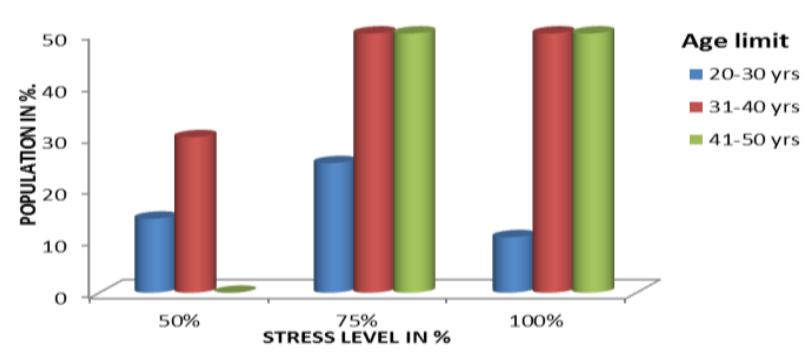

Fig 1 Stress level vs. age limit

III. Working Hours Vs. Stress Level

Table 2 Working Hours Vs Stress Level

\begin{tabular}{|r|c|c|c|}
\hline Stress level & \multicolumn{3}{|c|}{ working hours } \\
\cline { 2 - 4 } & $\mathbf{5 - 6}$ hrs & $\mathbf{7 - 9}$ hrs & $\mathbf{1 0 - 1 2}$ hrs \\
\hline $50 \%$ & 32 & 14 & 7 \\
\hline $75 \%$ & 16 & 29 & 44 \\
\hline $100 \%$ & 29 & 30 & 57 \\
\hline
\end{tabular}

It is clearly seen from the Table 2 and Fig 2 that the women who are 50\% stressed work for 5-6 hours, 75\% and $100 \%$ stressed women work for 7-12 hours. This explains that there is a direct impact of working hours on the stress percentage undergone by the working women. This may be due to the nature of work they undergo which leads to physical and mental tiredness.

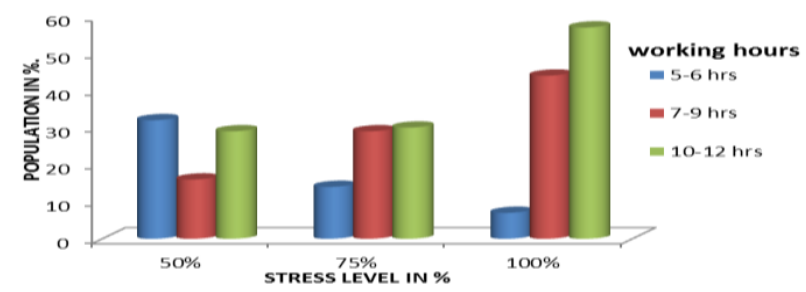

Fig 2 Working hours vs. stress level

\section{Reason For Working Vs. Age Limit}

The main reason for working is found to be the need for fulfilling their career goal among the younger women community while the older women community work for extra income. There is a very less women who work for spending the leisure time. It was already shown in Table 1 and Fig 1 that the stress in women increases in direct proportionality to their age; hence the reason of working for extra income by the older women may also increase their stress level.

Table 3 Reason for Working Vs Age Limit

\begin{tabular}{|c|c|c|c|}
\hline Age limit & $\begin{array}{c}\text { Need extra } \\
\text { income }\end{array}$ & $\begin{array}{c}\text { To fulfill career } \\
\text { goal }\end{array}$ & Leisure time \\
\hline $20-30 \mathrm{yrs}$ & 39 & 60 & 0 \\
\hline $31-40 \mathrm{yrs}$ & 70 & 57 & 10 \\
\hline $41-50 \mathrm{yrs}$ & 100 & 50 & 0 \\
\hline
\end{tabular}




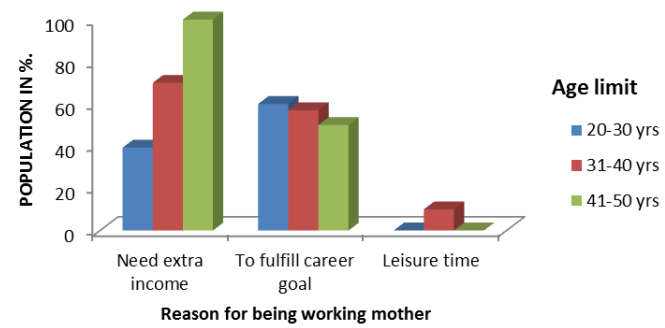

Fig 3 Reason for working vs. age limit

\section{Childcare Vs. Child Age}

In the olden days women were only home makers and hence they can take good care of their children, but now - $\mathrm{a}-$ days there is a necessity for the women to work for various reasons such as need for extra income, etc as seen in Table 4 and Fig 4. In such occasions there is a requirement for the working women to make arrangements for taking care of their children until they return home. It is found that the children under 2 years are taken care of relatives and the children above 18 years take care of themselves, only the children in the age group of 2-18 years are left in the care of Pre - school and Nanny. The mothers of such children contribute to the mid age working women group i.e., $31-40$ years. They have to make it on time from the source of child care which gives them extra tension to make up to and from the work place. Thus the child care arrangement may also lead to an additional stress component for women of this age group.

Table 4 Childcare and Child age

\begin{tabular}{|c|c|c|c|}
\hline Age limit & Pre-School & Nanny & Relatives \\
\hline under 2yrs & 0 & 0 & 100 \\
\hline $2-10$ yrs & 46 & 23 & 31 \\
\hline $11-18$ yrs & 100 & 0 & 0 \\
\hline
\end{tabular}

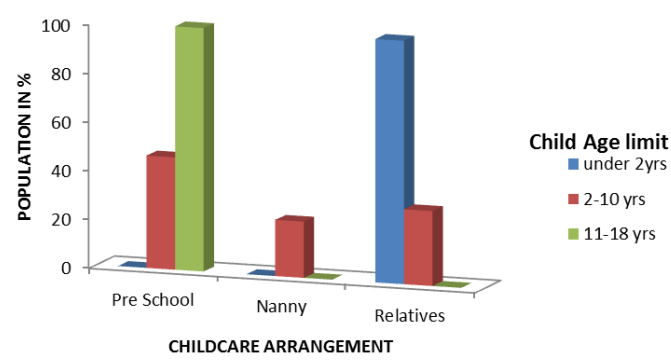

Fig 4 Childcare vs. child age

\section{Psychological Well Being}

The status of women in India has been subject to many great changes over the past few millennia. From equal status with men in ancient times through the low points of the medieval period, to the promotion of equal rights by many reformers, the history of women in India has been eventful. However, humiliation, harassment, torture and exploitation of women are as old as is the history of family life. They are discriminated against at work and are denied their due in every field. Table 5 and Fig 5 give the details of the response of working women to such harassment. When harassed, the women in the age group of $20-30$ years wish to quit the job and some would like to fight for justice. This is because the women in this age group are mostly newly married and hence do not have enough courage to face the situation without any support. Whereas the women in the age group of $31-50$ years are willing to fight against injustice. The women of this age group have more family support and so are daring to face these issues.

Table 5 Psychological Well Being

\begin{tabular}{|c|c|c|c|c|}
\hline \multirow{2}{*}{ Age limit } & \multicolumn{4}{|c|}{ Decision when harassed } \\
\cline { 2 - 5 } & $\begin{array}{c}\text { Silent } \\
\text { spectator }\end{array}$ & $\begin{array}{c}\text { Suffer in } \\
\text { silence }\end{array}$ & $\begin{array}{c}\text { Quit the } \\
\text { job }\end{array}$ & $\begin{array}{c}\text { Fight against } \\
\text { injustice }\end{array}$ \\
\hline $20-30 \mathrm{yrs}$ & 4 & 0 & 36 & 29 \\
\hline $31-40 \mathrm{yrs}$ & 10 & 10 & 20 & 70 \\
\hline $41-50 \mathrm{yrs}$ & 0 & 0 & 0 & 50 \\
\hline
\end{tabular}




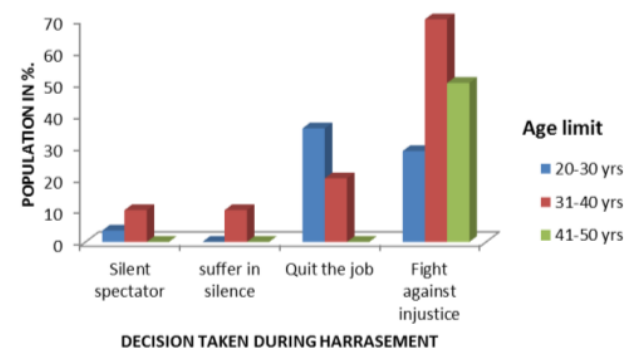

Fig 5 Psychological well being

\section{Work Life Balance}

It is required for the married working women to maintain a complete balance between work and life. They need to manage the family and work simultaneously in a balanced manner. From Table 6 and Fig 6 it is clear that the women with higher age are not able to maintain a balance between the family and life. As studied by Campbell et al [7] on the effects of family life on women's job performance and work attitudes, the women with children were significantly lower in occupational commitment relative to women without children, contrary to expectation, women with younger children out performed women with older children.

Table 6 Work Life Balance

\begin{tabular}{|c|c|c|}
\hline \multirow{2}{*}{ Age limit } & \multicolumn{2}{|c|}{ work life balance } \\
\cline { 2 - 3 } & Balanced & Not Balanced \\
\hline $20-30 \mathrm{yrs}$ & 46 & 14 \\
\hline $31-40 \mathrm{yrs}$ & 20 & 70 \\
\hline $41-50 \mathrm{yrs}$ & 0 & 100 \\
\hline
\end{tabular}

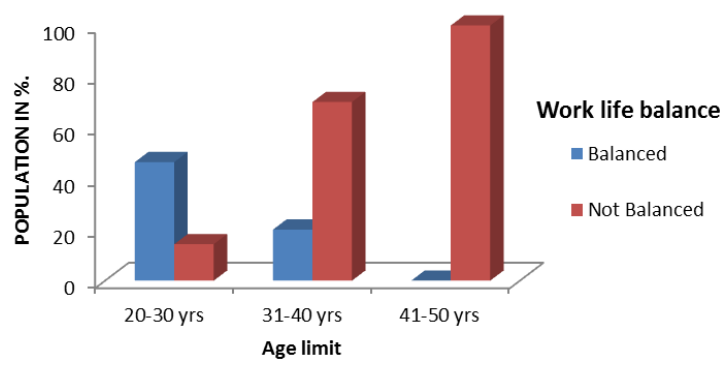

Fig 6 Work life balance

VIII. Stress Management Through Institutionalsupport

The stress can be managed if the institution provides a helping hand for the working women. From Table 7 and Fig 7 it is seen that the women in the age group $20-30$ years depend on the superior's and subordinate's support to manage stress, the women in age group $31-40$ years depend on the paid and unpaid leaves and the women of $41-50$ years can manage stress with their subordinate's support. The women of 20-30 years are in the entering phase of job and so depends on their superiors, similarly the women in the age group of $41-50$ years depend on their subordinates as most of them are in the middle phase of management. But the women of $31-40$ years are subject to higher family commitments and hence they are in need of paid or unpaid leave to manage their stress.

Table 7 Stress Management through Institutional Support

\begin{tabular}{|c|c|c|c|}
\hline Age limit & $\begin{array}{c}\text { Superior's } \\
\text { Support }\end{array}$ & $\begin{array}{c}\text { Subordinate's } \\
\text { Support }\end{array}$ & $\begin{array}{c}\text { Paid/unpaid } \\
\text { leave }\end{array}$ \\
\hline $20-30$ yrs & 50 & 50 & 21 \\
\hline $31-40$ yrs & 60 & 50 & 80 \\
\hline $41-50$ yrs & 50 & 50 & 0 \\
\hline
\end{tabular}




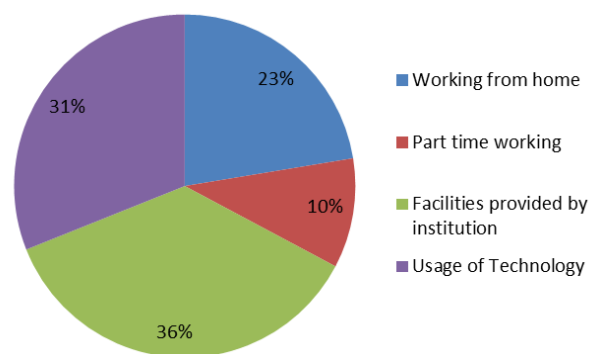

Fig 7 Stress relief through institutional support

\section{Health Problems In Workingwomen}

Stress causes many health issues such as frequent headache, hypertension, obesity, etc., women susceptible to stress are also susceptible to face some common health problems. The Table 8 and Fig 8 show that due to stress at workplace most of the working women undergo frequent headache and hypertension. A few stressed women are vulnerable to hypertension and obesity.

Table 8 Health Problems in Working Women

\begin{tabular}{|l|c|}
\hline $\begin{array}{l}\text { Health Problems Faced } \\
\text { by women }\end{array}$ & $\begin{array}{c}\text { Population } \\
\text { in \%. }\end{array}$ \\
\hline Hypertension & 16 \\
\hline Obesity / Diabetes & 11 \\
\hline Frequent headaches & 68 \\
\hline Others & 5 \\
\hline
\end{tabular}

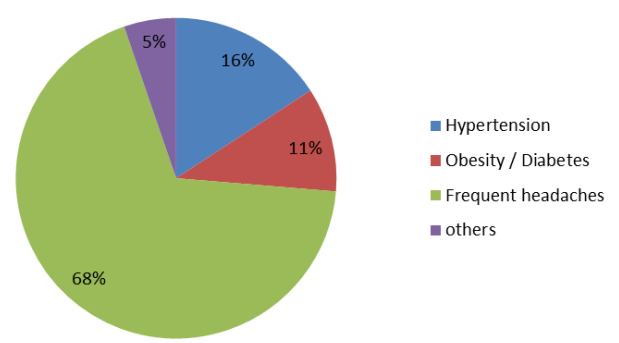

Fig 8 Health problems in working women

\section{Stress Relief Through Institutional Support}

The women of any age group feel that they can get rid of stress with the help of institutional support by either working part time or from home. It is found from Fig 9 and Table 9 that the facilities and technology provided by the institution provide a better stress relief for the working women.

Table 9 Stress Relief through Institutional Support

\begin{tabular}{|l|c|}
\hline Work Stress management & $\begin{array}{l}\text { Population } \\
\text { in \%. }\end{array}$ \\
\hline Working from home & 23 \\
\hline Part time working & 10 \\
\hline $\begin{array}{l}\text { Facilities provided by } \\
\text { institution }\end{array}$ & 36 \\
\hline Usage of Technology & 31 \\
\hline
\end{tabular}

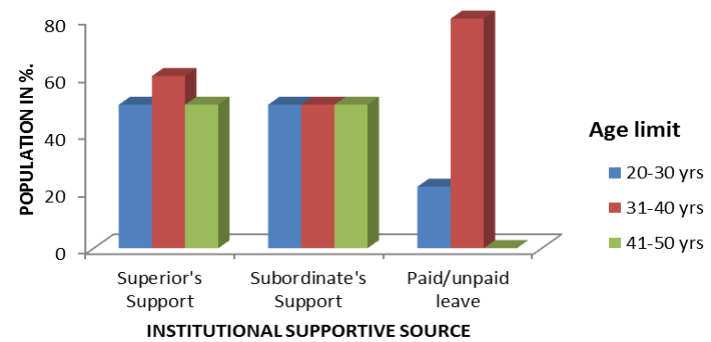

Fig 9 Stress management through institutional support 


\section{Stress Relief - Strategies}

The married working women are having high risk of stress and its impact, it is required for these women to follow stress relief strategies so that they can maintain a proper health and work life balance. From Table 10 and Fig 10 it is found that most of the married women relieve their stress by spending time on family and entertainment, yet some got rid of their stress through yoga and rest and a few of them tend to follow stress relief through spending time with pets and some other related sources.

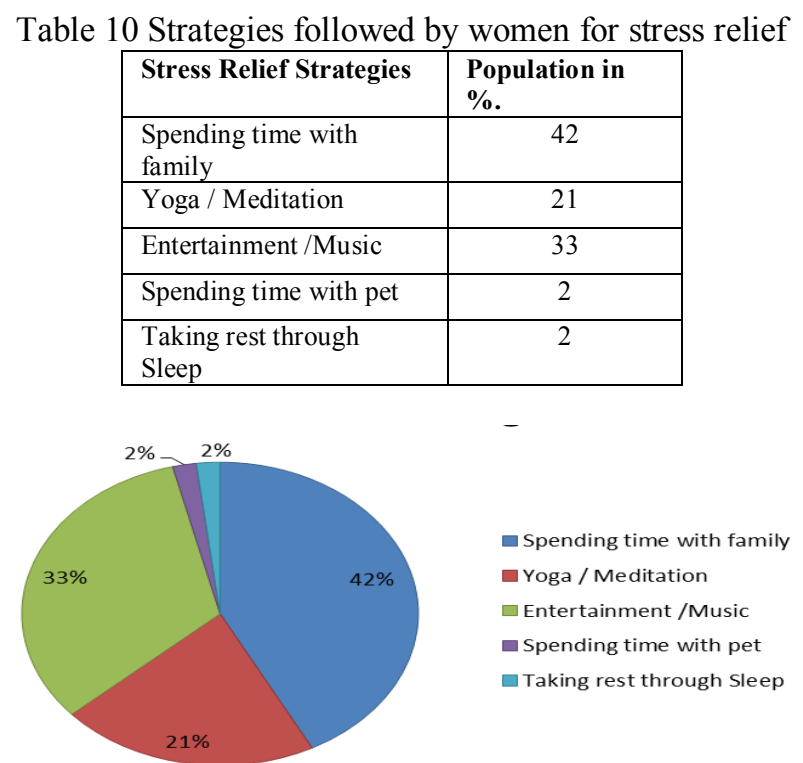

Fig 10 Strategies followed by women for stress relief

\section{Conclusions}

The following concluding remarks were framed from the current study on the stress in married working women.

1. The stress in women was found to be directly proportional to their age. This may be because of the additional responsibilities imposed on the elder women both in the family as well as workplace.

2. There is a direct impact of working hours on the stress percentage undergone by the working women. This may be due to the nature of work they undergo which leads to physical and mental tiredness.

3. The main reason for working is found to be the need for fulfilling their career goal among the younger women community while the older women community work for extra income. Hence, the reason of working for extra income by the older women leads to working out of compulsion which in turn results in increase of their stress level.

4. The mid age working women group i.e., 31 - 40 years are the working mothers of children in the age group of $2-18$ years. The child care arrangement may add to the stress component for women of this age group.

5. The response of married working women to harassment is that the women in the age group of $20-30 \mathrm{yrs}$ wish to quit the job and some would like to fight for justice. This is because the women in this age group are mostly newly married and hence have less courage to face the situation without any support. Whereas the women in the age group of $31-50$ years are willing to fight against injustice as they have more family support to face these issues.

6. The women with higher age are not able to maintain a balance between the family and work. The effects of family life on women's job performance and work attitudes affect the women with children were significantly lower in occupational commitment relative to women without children; contrary to expectation, women with younger children outperformed women with older children.

7. The women susceptible to stress are also subjected to face some common health problems. The married working women are highly disposed to the risk of stress and its impact, it is required for these women to follow stress relief strategies so that they can maintain a proper health and work life balance. Due to stress at workplace, the stressed women are vulnerable to frequent headache, hypertension and obesity.

8. Stress can be well managed through institutional support. The women of 20-30 years are in the entering phase of job and so depends on their superiors, similarly the women in the age group of $41-50$ years depend on their subordinates as most of them are in the middle phase of management. But the women of 31 -40 years are subject to higher family commitments and hence in need of paid or unpaid leave to manage their stress. 
9. The facilities and technology provided by the institution give a better stress relief for the working women. The women of any age group feel that they can get rid of stress with the help of institutional support by either working part time or from home.

\section{Suggestions}

Stress is one of the major problems of working women in India. Many working women in India, especially those who are working mothers are stuck in stress and depression, forever trying to balance an ever-growing burden of professional responsibilities and personal commitments. There is an urgent need for them to overcome that stress and beat the depression.

1. The stress in elderly women can be reduced by sharing their personal works with the family members and official works with the subordinates at workplace.

2. Long working hours induces stress in married working women, such stress can be reduced by giving number of breaks between the working hours and providing some refreshment for overcoming physical and mental tiredness during working time. Also shift timings can be framed to reduce the working hours.

3. The married working women get trapped in stress by working out of compulsion to create a financial balance in the family. This type of stress can be dealt by providing the facility to work from home or by adopting flexible working hours.

4. The mid age working mothers undergo stress because of the child care arrangement . This type of stress can be reduced if the pre- schooling and schooling facilities are arranged within the working campus and by providing a staff quarters within the working campus.

5. The women should always fight against the harassments and this can only be achieved with their family support; even if they are either unmarried or newly married. A clear explanation about their situation to the family members will enable them the required family support to fight for justice against harassment.

6. It is required for the working women to maintain a complete work life balance and need to manage the family and work simultaneously in a balanced manner. Maintaining a complete work life balance reduces stress to a very great level. Scheduling one's work properly can give a satisfied work life balance.

7. Great level of stress is caused in women if they are not well supported by the organization. Thus such type of stress can be managed by following the organizational line of command and by providing various types of paid and unpaid leaves like sick leave, maternity leave, vacation leave, etc., Also, by providing both technological and non-technological facilities like laptops, transportation, accommodation, etc., the stress in working women can be reduced

8. The stress of married working women can be relieved through some stress relief techniques like spending time on family and entertainment, yoga and rest, etc.,

Thus in general stress in married working women is caused due to long working hours, various family and official commitments, harassments and improper work life balance. Such type of stress leads to various problems such as prolonged headaches, hypertension and obesity. Stress can be relieved with the help of institutional support, balancing work and life, by spending time with family, entertainments and yoga and rest.

\section{Referances}

[1] Prof. Parul Tripathi; Prof. Sandeep Bhattacharjee, A study on psychological stress of working women, International Journal of Multidisciplinary Research, 2(2), 2012,434 - 445.

[2] UnaizaNiaz, Sehar Hassan, The perception of professional women about their job and its effects on psychological well-being, Journal of Pakistan psychiatric society, 3(2), 2006, 83.

[3] Dr. M. Dhanabhakyam and V. Anitha, A study on stress management of working women in coimbatore district, International journal of multidisciplinary research, 1(7), 2011, 337- 344 .

[4] Iffat Hussain, Problems of working women in karachi, Pakistan (UK, Cambridge Scholars Publishing,2008)

[5] Ungsinan Intarakamhang, Research synthesis concerning stress and coping of Thai people, The Journal of Behavioral Science, 4 (1), $2009,36-48$.

[6] Vatiswa Veronica Makie, Stress and coping strategies amongst registered nurses working in a south African tertiary hospital, Magister Curationis, University Of The Western Cape, South Africa, 2006

[7] Donald J. Campbell, Kathleen M. Campbell, Daniel Kennard, The effects of family responsibilities on the work commitment and job performance of non-professional women, Journal of Occupational and Organizational Psychology, 67(4), 1994, 283 - 296. 